\title{
Two-step sol-gel synthesis of mesoporous aluminosilicates: highly efficient catalysts for the preparation of 3,5-dialkylpyridines
}

\author{
Marat R. Agliullin ${ }^{1,2}$ (D) Valentin P. Talzi ${ }^{3} \cdot$ Nadezhda A. Filippova $^{1} \cdot$ Vera R. Bikbaeva ${ }^{2} \cdot$ Sergey V. Bubennov $^{1}$. \\ Tatyana R. Prosochkina ${ }^{2} \cdot$ Nellya G. Grigorieva ${ }^{1,2} \cdot$ Nama Narender $^{4} \cdot$ Boris I. Kutepov $^{1,2}$
}

Received: 19 December 2017 / Accepted: 1 June 2018 / Published online: 26 June 2018

(c) The Author(s) 2018

\begin{abstract}
The microstructure, acid properties and characteristics of the porous structure of sol-gel-synthesized mesoporous aluminosilicates with $\mathrm{Si} / \mathrm{Al}$ ratios of 40, 80, and 120 have been investigated. It was illustrated that the main reason for the formation of a narrow mesopore size distribution in the investigated aluminosilicates is related to the close size of the secondary particles of the prepared xerogels. The research revealed that an increase in the Si/A1 ratio leads to a slight decrease in the specific surface and mesopore volume. An increase in the Si/Al ratio from 40 to 120 has proved to reduce the total acidity in ammonia from 554 to $324 \mu \mathrm{mol} / \mathrm{g}$. It is shown that mesoporous aluminosilicates prepared by two-step sol-gel synthesis show high activity and selectivity in the synthesis of 3,5-dialkylpyridines.
\end{abstract}

\section{Graphical abstract}

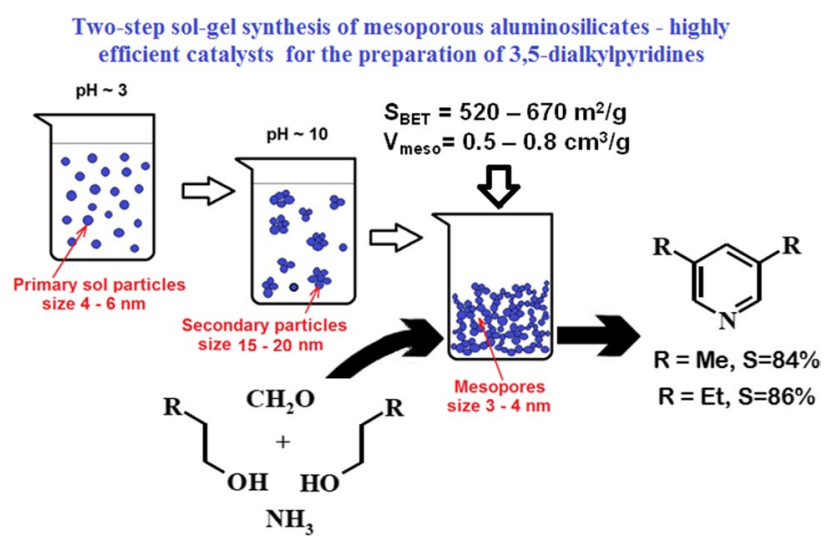

Keywords Heterogeneous catalysis $\cdot$ Mesoporous aluminosilicates $\cdot$ Multicomponent reactions $\cdot 3$,5-dialkylpyridines

Marat R. Agliullin

maratradikovich@mail.ru

1 Institute of Petrochemistry and Catalysis RAS, 141 Pr. Oktyabrya, Ufa 450075, Russian Federation

2 Ufa State Petroleum Technologica University, 1 Kosmonavtov Street, Ufa 450062, Russian Federation

3 Institute of Hydrocarbon Processing Problems Sb RAS, 54 St. Neftezavodskaya, Omsk 644040, Russian Federation

4 CSIR-Indian Institute of Chemical Technology, Uppal Road, Tarnaka, Hyderabad, Telangana 500 007, India

\section{Introduction}

Currently, sol-gel technology has become an integral feature of the modern practice of producing new materials with unique properties [1-9]. It is the basis of the latest technologies for the preparation of high-temperature superconducting oxides [3], ceramic ultrafiltration membranes [4], optical [5] and anticorrosive coatings [6], new biomaterials [7], porous sorbents or carriers [8, 9]. Furthermore, sol-gel synthesis is a powerful tool for 
controlling the formation of active sites and the porous structure of various heterogeneous catalysts at the stage of sol-gel processing $[10,11]$.

Sol-gel technology is widely used in the production of amorphous aluminosilicates that are part of the modern catalysts for cracking, hydrocracking, hydroisomerization of $n$-paraffins, biofuel processing, pyridine synthesis and many other important processes of oil refining and petrochemical industry [12-16].

Generally, industrially produced amorphous aluminosilicates are micro- or micro-mesoporous materials with a predominance of micropores. The presence of micropores reduces the diffusion rates of the reacting molecules and products of the catalytic transformations, resulting in a rapid deactivation of the catalyst. In addition, such materials are ineffective in the catalytic transformations of bulk molecules because of the transport limitations due to the parameters of their porous structure. Solutions for all of these problems will probably require preparation of aluminosilicates with a mesoporous structure, ensuring efficient diffusion of the reactants to the active sites and the reverse diffusion of the resulting reaction products.

Scientists attach great importance to mesoporous aluminosilicates synthesis by the prospects in application of in catalysis for the last 25 years [17-20]. Traditional methods for the synthesis of mesoporous aluminosilicates are based on the use of various templates unfortunately, in view of the high cost of the templates and their toxicity, these methods have not found industrial application.

We consider sol-gel technology a more promising way of preparing mesoporous aluminosilicates. Thus, aluminosilicates with different porous structures were prepared using the latter in [21-29]. It should be pointed out that these works do not address the issue of simultaneous formation of maximum acidity and mesoporous structure of the materials obtained, and this unresolved issue makes creation of highly efficient catalytic systems impossible.

We have prepared earlier mesoporous aluminosilicates with a high proportion of aluminum atoms embedded in a silicate matrix and a narrow pore size distribution applying sol-gel synthesis [30], which proved to be high efficiency catalysts for oligomerization of $\alpha$-olefins. This research focuses on a more detailed study of the mechanism of formation of mesopores with a narrow size distribution, study of the influence of the $\mathrm{Si} / \mathrm{Al}$ ratio in mesoporous aluminosilicates, prepared by two-step sol-gel synthesis, on their porous structure, the size of secondary gel particles, the localization of aluminum atoms and the acidity of the surface.

Moreover, the prospects of using mesoporous aluminosilicates, prepared by two-step sol-gel synthesis, as catalysts for the synthesis of 3,5-dialkylpyridines, are highlighted in this paper.
Pyridine and its derivatives are used as solvents and starting materials in the synthesis of a variety of practically important compounds such as insecticides, herbicides, drugs, vitamins, food flavors, feed additives, dyes, rubber chemicals, explosives, disinfectants and adhesives [31, 32]. 3,5-Dimethylpyridine is an important intermediate in the synthesis of antiulcer drugs (omeprazole, lansoprazole, rabeprazole) $[31,33]$, corrosion inhibitors, used as a catalyst in epoxide crosslinking reactions as a high-temperature solvent [34], etc. 3,5-Diethylpyridine is a useful intermediate for many drugs and a starting material for the preparation of 3,5-pyridinedicarboxylic acid [35].

Synthesis of 3,5-dimethylpyridine with a yield of up to $54.7 \%$ by the reaction of propionaldehyde and formaldehyde with ammonia in the presence of aluminosilicates promoted by ammonium halides is described by Van der Gaag et al. [36]. Kulkarni with co-authors [37] synthesized 3,5-dimethylpyridine with a yield of up to $63.1 \%$ by the reaction of propionaldehyde, formaldehyde and ammonia over ZSM-5 zeolites in H- and cationic form. The same authors studied [38] the interaction of propanol, formaldehyde and methanol with ammonia over modified ZSM-5 zeolites. The research showed that the selectivity of 3,5-dimethylpyridine is $72,2 \%$ over $\mathrm{La}-\mathrm{ZSM}-5(\mathrm{Si} / \mathrm{Al}=15)$ at $88.6 \%$ conversion of propanol.

The process for the preparation of 3,5-dimethylpyridine from 2-methyl-1,5-pentadiamine in the presence of alumina catalysts is described in the patent [34]. The yield of 3,5-lutidine is low and makes $12-23 \%$.

The method for the preparation of 3,5-diethylpyridine by the reaction of 1,1,1-trimethylolpropane with ammonia or amines at $240-400{ }^{\circ} \mathrm{C}$ in the presence of acid catalysts is presented in [39]. The yield of 3,5-diethylpyridine reaches $70 \%$. The authors [40] reported the synthesis of 3,5-diethylpyridine in $52.3 \%$ yield from butanol, formaldehyde and $\left(\mathrm{NH}_{4}\right)_{2} \mathrm{HPO}_{4}$ in the liquid-phase reaction in the patents [41, 42] it was proposed to obtain 3,5-diethylpyridine by gasphase condensation of butanol, formaldehyde and ammonia in the first case, an aluminosilicate catalyst is used, the yield of the desired product is very low making only $13-19 \%$. The authors of the second invention used an aluminochromiumnickel catalyst, which made it possible to increase the yield of 3,5-diethylpyridine to $36.5 \mathrm{~mol} \%$.

Previously, we studied the reaction of ethanol with formaldehyde and ammonia in the presence of zeolite catalysts with a micro- and micro-meso-macroporous structure, as well as mesoporous amorphous aluminosilicates [43]. It is shown that a sample of mesoporous aluminosilicate with $\mathrm{Si} /$ $\mathrm{Al}=40$ molar ratio, synthesized by the above described procedure, exhibits high activity and selectivity for picolines.

The results achieved encouraged further research on the synthesis of pyridines on mesoporous aluminosilicates. In this paper, we present the outcomes of studying the catalytic 
properties of mesoporous aluminosilicates prepared by a two-step sol-gel synthesis with different $\mathrm{Si} / \mathrm{Al}$ ratios in the synthesis of 3,5-dialkylpyridines by reaction of $n$-alcohols $\mathrm{C}_{3}-\mathrm{C}_{4}$ with formaldehyde and ammonia.

\section{Experimental}

\section{Materials}

Tetraethylorthosilicate (TEOS, 98\%, Acros Organics), Aluminium nitrate $\left(\mathrm{AL}\left(\mathrm{NO}_{3}\right)_{3} \cdot 9 \mathrm{H}_{2} \mathrm{O}, 99 \%\right.$, Merck), Ethanol $\left(\mathrm{C}_{2} \mathrm{H}_{5} \mathrm{OH}, 96 \%\right.$, Acros), Aqueous ammonia (30\%, Acros), and deionized water. All chemicals were used as received without further purification.

Propanol (99.5\%, Acros), Butanol (99\%, Acros), aqueous solutions of formaldehyde (37\%) were used with no additional purification.

\section{Sol-gel synthesis of mesoporous aluminosilicates}

Mesoporous aluminosilicates with $\mathrm{Si} / \mathrm{Al}=40,80,120$ atomic ratio have been prepared by sol-gel synthesis at variable $\mathrm{pH}$ [30]. In a typical synthesis in the first step (synthesis in an acidic medium), $14 \mathrm{~g}$ of tetraethylorthosilicate and $0.16-0.64 \mathrm{~g}(0.16 \mathrm{~g}$ for $\mathrm{Si} / \mathrm{Al}=120,0.32 \mathrm{~g}$ for $\mathrm{Si} / \mathrm{Al}=80$, $0.64 \mathrm{~g}$ for $\mathrm{Si} / \mathrm{Al}=40$ ) of aluminum nitrate were added to $12 \mathrm{ml}$ of water and $28 \mathrm{ml}$ of ethanol. The initial solution with $\mathrm{pH} 3 \mathrm{had}$ been kept in a thermostat at $58-60{ }^{\circ} \mathrm{C}$ for $20-30 \mathrm{~h}$ until the gel point was reached. Then, in the second step (synthesis in an alkaline medium), $6.3 \mathrm{~g}$ of aqueous ammonia solution was added to the gel with vigorous stirring until $\mathrm{pH} 10$ was reached, followed by kept at $25^{\circ} \mathrm{C}$ for $24 \mathrm{~h}$.

Then, based on the results, all prepared gels were subjected to stepwise thermal treatment at $50{ }^{\circ} \mathrm{C}(12 \mathrm{~h}), 150{ }^{\circ} \mathrm{C}$ $(24 \mathrm{~h})$ and $650{ }^{\circ} \mathrm{C}$ for $5 \mathrm{~h}$. To investigate the catalytic properties of aluminosilicates, they were crushed to fine powders of the fractional composition from 20 to $100 \mu \mathrm{m}$. The samples with $\mathrm{Si} / \mathrm{Al}$ ratio of 40,80 and 120 are indicated as ASM-40, ASM-80 and ASM-120, respectively.

\section{Physical and chemical studies of the obtained materials}

The chemical composition of the prepared aluminosilicates was analyzed on a EDX 720/900HS Shimadzu X-ray fluorescent spectrometer.

Diffraction patterns were recorded using Rigaku Ultima IV diffractometer in the monochromatic $\mathrm{Cu} \mathrm{K} \alpha$ emission within the $2 \theta$ angle range of $3^{\circ}-50^{\circ}$ in $0.5^{\circ} \mathrm{C} / \mathrm{min}$ increments and the $20 \mathrm{~s}$ integration time at each point.

The coordination sphere of aluminum atoms in the calcined samples was evaluated by the ${ }^{27} \mathrm{Al}$ MAS NMR spectra. the spectra were obtained using Avance- 400 "Bruker" spectrometer equipped with the multi-nuclear sensor in the simple single pulse experiment under the $\sim 104 \mathrm{~Hz}$ magic angle spinning of the samples in zirconium dioxide rotors. The aqueous $1 \mathrm{~mol} / \mathrm{l} \mathrm{AlCl}_{3}$ solution was used for the external reference standard.

The porous structure was characterized by the low temperature $(77 \mathrm{~K})$ nitrogen adsorption-desorption using the ASAP-2020 "Micromeritics" sorption meter. Prior to the analysis the samples were vacuum-treated at $350{ }^{\circ} \mathrm{C}$ for $6 \mathrm{~h}$. The specific surface area was calculated by the BET method at the relative partial pressure of $p / p_{0}=0.2$. The pore size distribution was calculated by the BJH (Barrett-Joyner-Halenda) desorption curve; the total pore volume was determined by the $\mathrm{BJH}$ method at the relative partial pressure of $p / p_{0}=0.98$. The volume of the micropores in the presence of mesopores was determined by means of the t-plot method.

The sol particle size distribution in the liquid phase was determined by SAXS (Small-Angle X-Ray scattering) technique. Small angle scattering curves of the samples were obtained using a HECUS bench-scale setup with the X-ray tube equipped with a copper anode of the wavelength of $\lambda$ $(\mathrm{Cu} \mathrm{K} \alpha)=1.54 \AA$ as the radiation source. Processing of the small-angle scattering curves was performed according to the technique as previously described [44].

The morphology of the samples was studied using a Hitachi transmission electron microscope (TEM). Images were acquired in bright-field TEM mode at $100 \mathrm{kV}$ accelerating voltage. Target-oriented approach was utilized for the optimization of the analytic measurements [45]. Before measurements the samples were mounted on a $3 \mathrm{~mm}$ copper grid and fixed in a grid holder.

Acid properties of aluminosilicates were studied by the temperature programmed desorption of ammonia [46] (TPD $\mathrm{NH}_{3}$ ) and infrared spectroscopy (IR-spectroscopy) using the low temperature adsorption of the $\mathrm{CO}$ probe molecule [47].

\section{Catalytic properties of the materials obtained in the synthesis of 3,5-dimethylpyridine}

Prior to catalytic testing, the catalyst samples had been heattreated at $540{ }^{\circ} \mathrm{C}$ in an air atmosphere for $3 \mathrm{~h}$. The reaction of alcohols ( $n$-propanol, $n$-butanol) with formaldehyde and ammonia was carried out in a fixed-bed flow reactor at $300-400{ }^{\circ} \mathrm{C}$, atmospheric pressure, $2-14 \mathrm{~h}^{-1}$ feed space velocity of alcohol: $\mathrm{CH}_{2} \mathrm{O}: \mathrm{NH}_{3}=1.0: 0.8: 3.0$ molar ratio. The amount of catalyst added in the reactor was $1 \mathrm{~g}$. At the end of the synthesis, the reactor was purged with nitrogen for $30 \mathrm{~min}$. The product was collected in an ice-cooled receiver located at the bottom of the unit. The reaction products were extracted with diethyl ether. After distilling off the ether, the residual matter was analyzed by gas-liquid

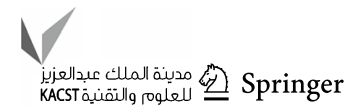


chromatography on Shimadzu GS-2014 chromatograph with a flame ionization detector ( $25 \mathrm{~m}$ long glass capillary column, SE-30 phase, $50-280{ }^{\circ} \mathrm{C}$ analysis temperature with programmed heating of $8{ }^{\circ} \mathrm{C} / \mathrm{min}, 250^{\circ} \mathrm{C}$ temperature of the detector, $300{ }^{\circ} \mathrm{C}$ evaporator temperature, helium as carrier gas-30 $\mathrm{ml} / \mathrm{min}$ ).

\section{Results and discussion}

\section{Chemical and phase composition of the materials obtained}

The analysis results show that the $\mathrm{Si} / \mathrm{Al}$ atomic ratio in all calcined aluminosilicate samples is close to the $\mathrm{Si} / \mathrm{Al}$ ratio in the initial solution (Table 1).

Figure 1 shows the X-ray patterns of the synthesized samples. For all samples, a halo at around $2 \theta=20-30$ is observed, indicating the formation of an exclusively amorphous material.

\section{Localization of aluminum atoms in the silicate framework according to the data ${ }^{27}$ AI MAS NMR}

It is known [46] that Brønsted acid sites are formed while the aluminum atoms are introduced into the silicate framework in the aluminosilicates. Moreover, the aluminum atoms are characterized by a tetrahedral environment in oxygen with a signal in the ${ }^{27} \mathrm{Al}$ MAS NMR spectra from 50 to $60 \mathrm{ppm}$. Part of the aluminum atoms that did not enter the silicate framework can form the extrastructural $\mathrm{Al}_{2} \mathrm{O}_{3}$ microphases, with the signal in ${ }^{27} \mathrm{Al}$ MAS NMR spectra from 0 to $20 \mathrm{ppm}$.

Figure 2 shows the ${ }^{27} \mathrm{Al}$ NMR spectra of the synthesized samples. It shows that on all spectra there is a main signal from 50 to $60 \mathrm{ppm}$ and a weak signal from 0 to $10 \mathrm{ppm}$. The results show a high proportion of aluminum atoms included in the silicate framework with the predominant formation of the BAS (Brønsted Acid Sites). With an increase in the Si/ $\mathrm{Al}$ ratio in aluminosilicates, the share of the signal decreases from 0 to $10 \mathrm{ppm}$ and an the fraction of the signal increases from 50 to $60 \mathrm{ppm}$, pointing to a better introduction of aluminum atoms with a lower $\mathrm{Si} / \mathrm{Al}$ ratio.

Table 1 Chemical compositions of aluminosilicates

\begin{tabular}{lll}
\hline Sample & \multicolumn{2}{c}{ Chemical compositions } \\
\cline { 2 - 3 } & Initial compositions & $\begin{array}{l}\text { Calcined } \\
\text { aluminosili- } \\
\text { cates }\end{array}$ \\
\hline ASM-40 & $\mathrm{Si}_{40.11} \mathrm{Al}_{1.00}$ & $\mathrm{Si}_{40.07} \mathrm{Al}_{1.00}$ \\
ASM-80 & $\mathrm{Si}_{80.09} \mathrm{Al}_{1.00}$ & $\mathrm{Si}_{80.10} \mathrm{Al}_{1.00}$ \\
ASM-120 & $\mathrm{Si}_{120.12} \mathrm{Al}_{1.00}$ & $\mathrm{Si}_{120.22} \mathrm{Al}_{1.00}$ \\
\hline
\end{tabular}

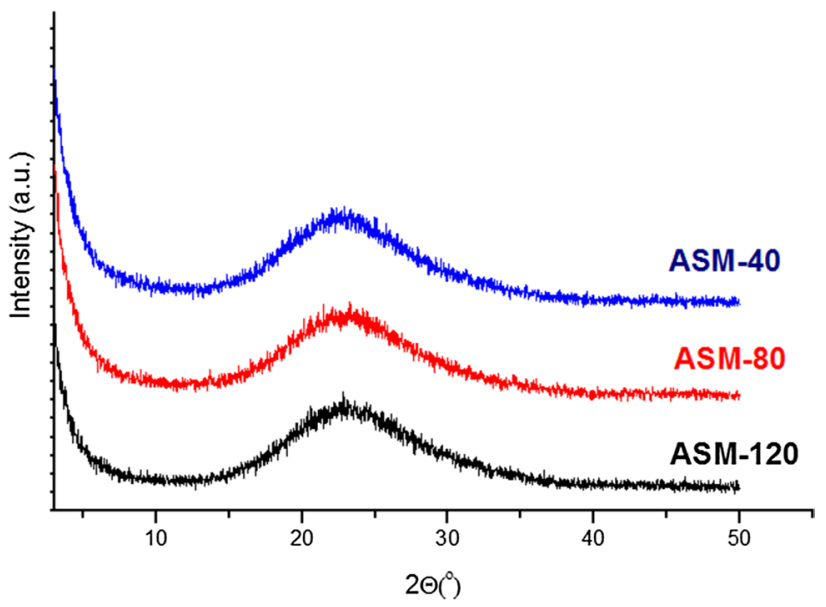

Fig. 1 Powder X-ray diffraction of aluminosilicates

\section{The influence of the $\mathrm{Si} / \mathrm{Al}$ ratio on the characteristics of the porous structure}

Figure 3 shows nitrogen adsorption-desorption isotherms and pore size distribution for ASM-40, ASM-80 and ASM120 samples. We can see that there is an isotherm of type IV with a hysteresis loop of type H1 according to the IUPAC classification, characteristic of mesoporous materials, for all samples. In the pressure region ranging from 0.98 to 1.00 , a sharp rise indicating the presence of macropores is observed.

Further, all samples exhibit a narrow pore size distribution in the range of $2-5 \mathrm{~nm}$ (Fig. 3), and the change in the $\mathrm{Si} / \mathrm{Al}$ ratio has practically no effect on the value of this parameter.

Table 2 provides the characteristics of the porous structure by the adsorption-desorption data of nitrogen. Apparently, the ASM-40 sample has a microporous volume of $0.05 \mathrm{~cm}^{3} / \mathrm{g}$, a mesopore volume of $0.5 \mathrm{~cm}^{3} / \mathrm{g}$ and

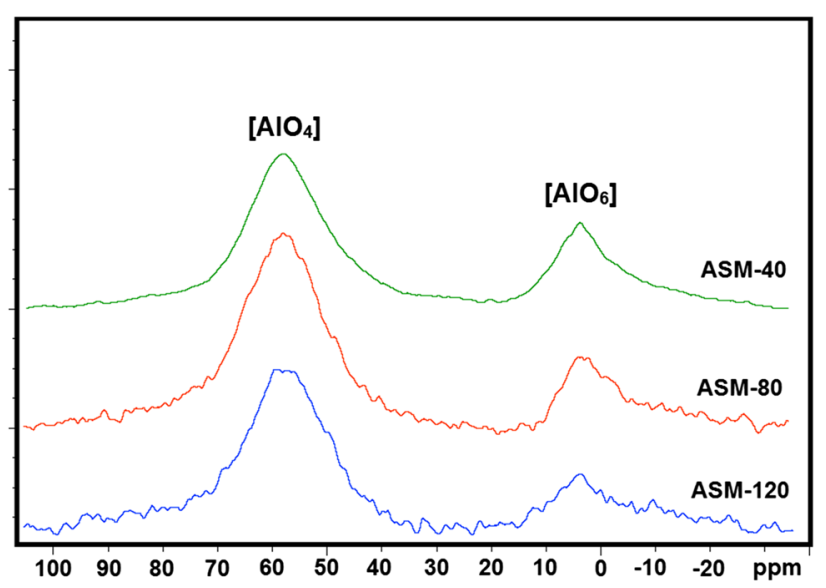

Fig. $2{ }^{27} \mathrm{Al}$ MAS NMR spectra of aluminosilicates 

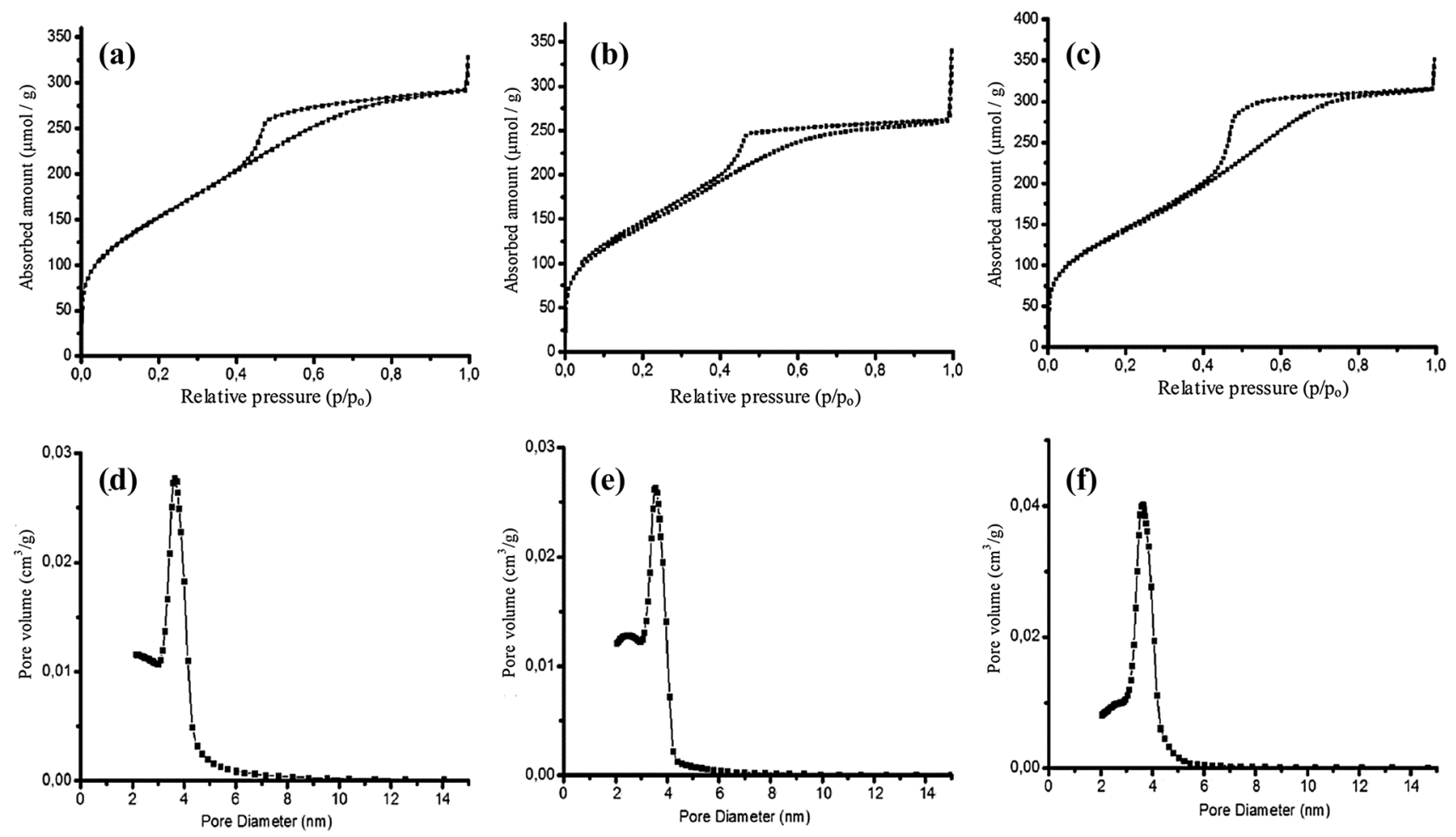

Fig. 3 Nitrogen sorption isotherms and pore size distribution for aluminosilicates: a ASM-40; b ASM-80; c ASM-120; d ASM-40; e ASM-80; f ASM-120

Table 2 Effect of $\mathrm{Si} / \mathrm{Al}$ on the characteristics of the porous

\begin{tabular}{lrlllll}
\hline Sample & Si/Al & $A_{\text {BET }}^{\mathrm{a}}\left(\mathrm{m}^{2} / \mathrm{g}\right)$ & $V_{\text {micro }}^{\mathrm{b}}\left(\mathrm{cm}^{3} / \mathrm{g}\right)$ & $V_{\text {meso }}^{\mathrm{c}}\left(\mathrm{cm}^{3} / \mathrm{g}\right)$ & $\begin{array}{l}\text { Particle } \\
\text { size }^{\mathrm{d}}(\mathrm{nm})\end{array}$ & Particle size $^{\mathrm{e}}(\mathrm{nm})$ \\
\hline ASM-40 & \multicolumn{1}{c}{40} & 670 & 0.05 & 0.50 & $4-6$ & $10-15$ \\
ASM-80 & 80 & 640 & 0.05 & 0.71 & $4-6$ & $10-15$ \\
ASM-120 & 120 & 520 & 0.05 & 0.80 & $4-6$ & $10-15$ \\
\hline
\end{tabular}

${ }^{\text {a }}$ Surface area calculated by the Brunauer-Emmett-Teller (BET) method

${ }^{\mathrm{b}}$ Micropore volume

${ }^{\mathrm{c}}$ Mesopore volume

${ }^{\mathrm{d}}$ Determined by SAXX

${ }^{\mathrm{e}}$ Determined by TEM

BET specific surface of $670 \mathrm{~m}^{2} / \mathrm{g}$. The ASM- 120 sample has a specific surface area of $520 \mathrm{~m}^{2} / \mathrm{g}$, and the micro- and mesopore volumes are 0.05 and $0.80 \mathrm{~cm}^{3} / \mathrm{g}$, respectively. Thus, an increase of the $\mathrm{Si} / \mathrm{Al}$ ratio in aluminosilicates results in an insignificant decrease in the specific surface and an increase in the mesopore volume are observed.

\section{The influence of the Si/Al ratio in the gel in the first step of the synthesis on the particle size of the sol according to the SAXS and TEM data}

It is known that the porous structure of the materials obtained by the sol-gel method is largely dependent on the size, the shape of the primary particles of the sol and their links to each other [11]. Figure 4a shows the particle size distribution of the sol obtained for the ASM-80 gel before the gel point at the first step of the synthesis (in acidic medium). We can see that the size of primary particles ranges from 4 to $6 \mathrm{~nm}$, similar results are observed for the ASM-40 and ASM-120 samples (Table 2).

Apparently, because of a relatively equal value of $\mathrm{pH} \sim 3$, for all initial solutions in the first step of synthesis, there are no large differences in supersaturations in the nucleation centers, resulting in a relatively equal size of the primary particles of the sol. 

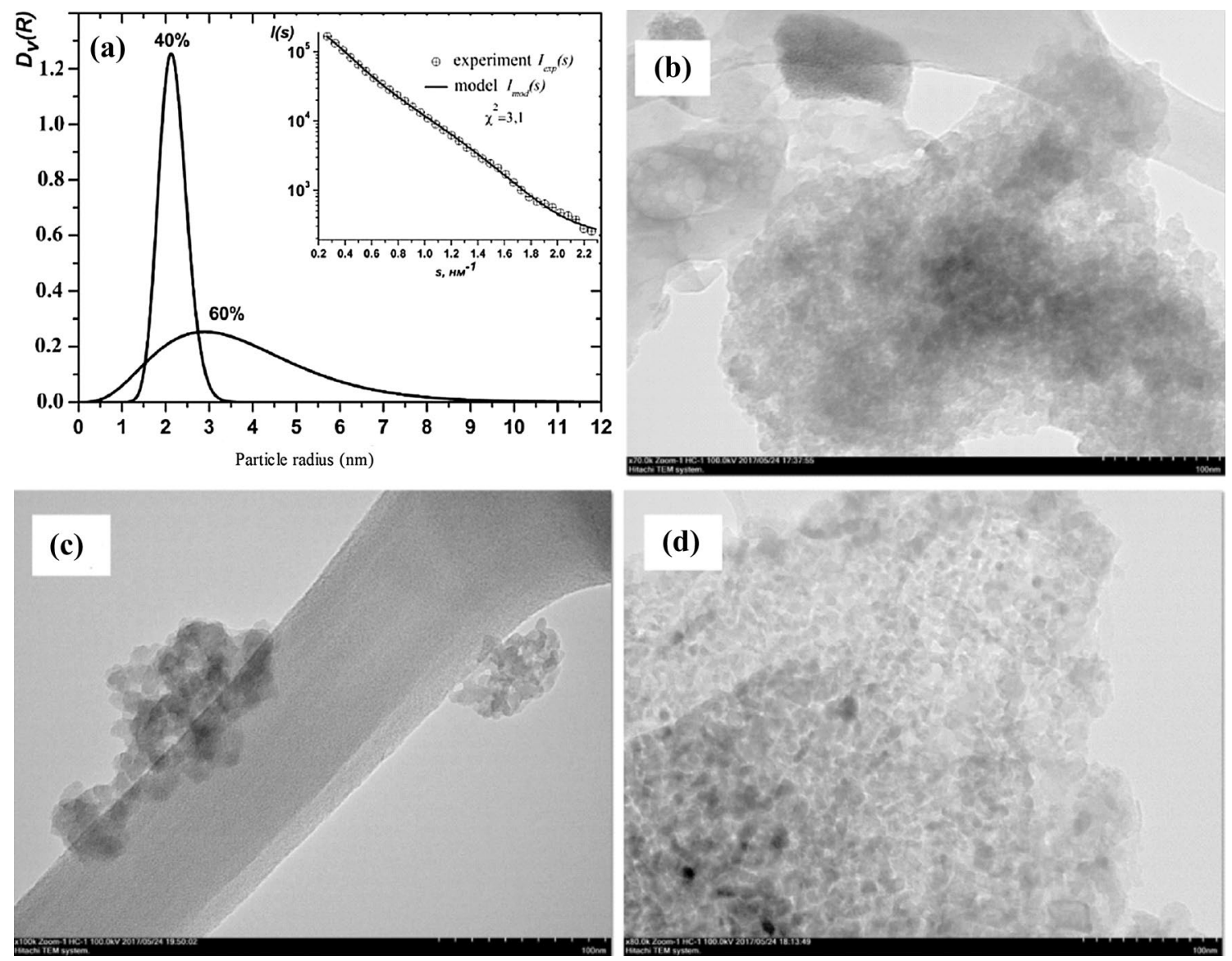

Fig. 4 The particle size distribution of the sol for gel in the gel point (a). TEM images of aluminosilicates: ASM-40 (b); ASM-80 (c); ASM-120 (d)

Figures 4b-d show pictures for ASM-40, ASM-80 and ASM-120 samples obtained by transmission electron microscopy. One can see that the porous structure for all samples is framed by spherical particles with a size of $10-15 \mathrm{~nm}$, which are not densely packed together. The voids formed between the particles are mesopores. It should be noted that particles with a size of $10-15 \mathrm{~nm}$ consist of smaller particles with a size of 4-6 nm. Thus, mesopores in these materials are formed between particles of similar size, which is the main reason for the formation of a narrow mesopore size distribution.

\section{The influence of the Si/Al ratio on the acidity of the surface}

Table 3 shows the TPD $\mathrm{NH}_{3}$ data for the ASM-40, ASM-80 and ASM-120 samples. As shown, increasing $\mathrm{Si} / \mathrm{Al}$ ratio reduces the total acidity values, which is common for all aluminosilicate systems [46]. The noteworthy feature here is that the total acidity values for the ASM-40 and ASM- 80 samples are relatively equal, although the aluminum content in ASM-40 is twice as high as in ASM-80. The results obtained are due to the fact that, because of the limited possibility of introducing aluminum atoms into the silicate framework the amount of the latter in ASM-40 and ASM-80 samples is relatively equal. The remaining aluminum atoms in the ASM-40 sample are present, presumably in the form of clusters of aluminum oxide.

Figure 5a shows the IR spectrum of the ASM-80 sample in the valence vibrations region of $\mathrm{OH}$ groups. In the spectrum of the sample, absorption bands (a.b.) of six types of hydroxyl groups are pointed out. The weak broad band at $3400-3650 \mathrm{~cm}^{-1}$ is classified as hydroxyl groups perturbed by hydrogen bonding with neighboring $\mathrm{OH}$ groups [48]. By analogy with zeolites, a.b. $3615-3620 \mathrm{~cm}^{-1}$ may be classified as acidic bridged hydroxyl groups $\mathrm{SI}-\mathrm{O}(\mathrm{H})-\mathrm{Al}$. It is difficult to classify a.b. $3650 \mathrm{~cm}^{-1}$. Presumably, it can belong to the category of acidic bridged hydroxyl groups $\mathrm{SI}-\mathrm{O}(\mathrm{H})-\mathrm{Al}$ in large pores or to $\mathrm{Al}-\mathrm{O}(\mathrm{H})-\mathrm{Al}$ groups [49]. The bands $3615-3620$ and $3650 \mathrm{~cm}^{-1}$ in the presented spectrum are not clearly defined, but are clearly distinguishable in the difference spectra after adsorption of $\mathrm{CO}$ (Fig. 5b). The triplet of a.b. 3730,3742 and $3747 \mathrm{~cm}^{-1}$ characterizes the terminal $\mathrm{Si}-\mathrm{OH}$ groups, and the first two points can be 
Table 3 Type and concentration of LAS and BAS according to FTIR spectroscopy of adsorbed CO and TPD $\mathrm{NH}_{3}$

\begin{tabular}{|c|c|c|c|c|c|c|}
\hline \multirow{2}{*}{$\begin{array}{l}\text { Type of acid sites } \\
\nu\left(\mathrm{cm}^{-1}\right)\end{array}$} & \multicolumn{3}{|l|}{ Lewis acid sites } & \multicolumn{2}{|c|}{ Brønsted acid sites } & \multirow{2}{*}{$\begin{array}{l}\mathrm{TPD} \mathrm{\Sigma NH}_{3} \\
150-550^{\circ} \mathrm{C}\end{array}$} \\
\hline & $v_{\mathrm{co}}=2231-2223$ & $\nu_{\mathrm{co}}=2212-2210$ & $\nu_{\mathrm{co}}=2202-2190$ & $\nu_{\mathrm{OH}}=3615$ & $\nu_{\mathrm{OH}}=3725-3740$ & \\
\hline The strength of sites & - & - & - & $\Delta \nu_{\mathrm{OH}}=300$ & $\Delta \nu_{\mathrm{OH}}=270-320$ & - \\
\hline Sample & \multicolumn{6}{|c|}{ Concentration $(\mu \mathrm{mol} / \mathrm{g})$} \\
\hline ASM-40 & 78 & 19 & 65 & 8 & 42 & 554 \\
\hline ASM-80 & 58 & 11 & 50 & 5 & 23 & 427 \\
\hline ASM-120 & 34 & 8 & 32 & 3 & 12 & 324 \\
\hline
\end{tabular}

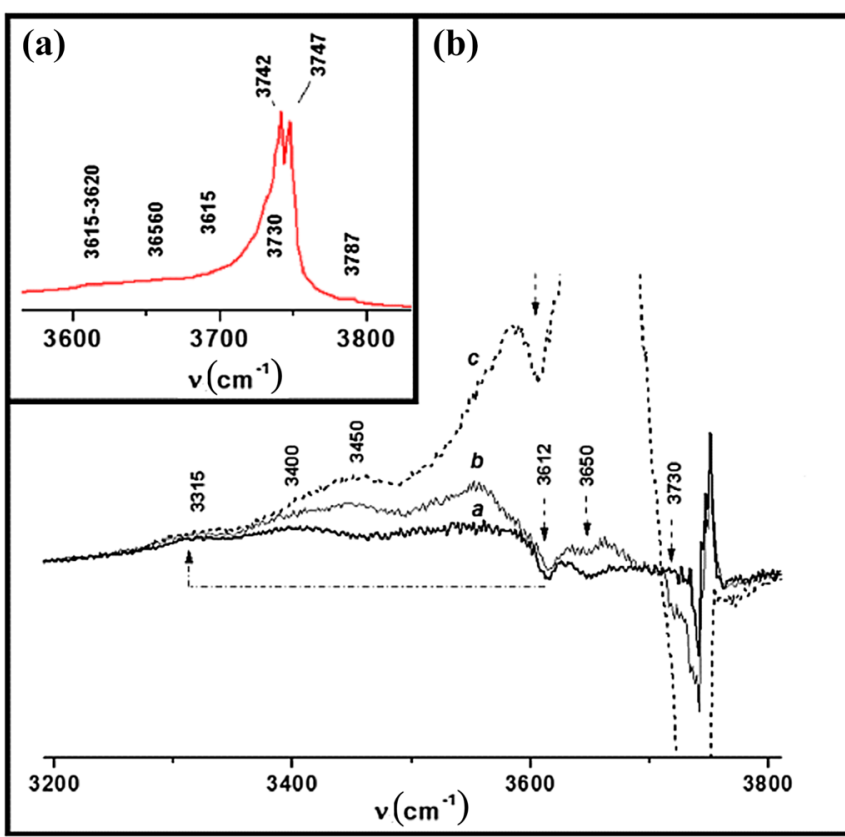

Fig. 5 a FTIR spectra of aluminosilicate ASM-80; b IR difference spectra in the OH-region for the ASM-80 sample before and after the adsorption: (a) 0.2; (b) 0.3; (c) 5 TORR CO; c IR difference spec-

classified as $\mathrm{Si}-\mathrm{OH}$ groups near surface defects [48]. The $3730 \mathrm{~cm}^{-1}$ signal presumably refers to the vibrations of the acidic $\mathrm{Si}-\mathrm{OH}$ groups located in the immediate vicinity of the LAS formed by three-coordinated $\mathrm{Al}$ or $\mathrm{Si}$ atoms ( $\mathrm{Si}-\mathrm{O}$ $\left.(\mathrm{H}) \ldots \mathrm{Al}^{3+}\right)[49,50]$. A signal of $3742 \mathrm{~cm}^{-1}$ is observed in the spectrum of the sample after vacuum processing at room temperature, which suggests the non-acidity of these groups. The $3787 \mathrm{~cm}^{-1}$ band characterizes terminal $\mathrm{Al}-\mathrm{OH}$ groups; similar absorption bands are observed for ASM-40 and ASM-160 samples.

It is known that a $\mathrm{CO}$ probe molecule, which is a weak base, can be used to evaluate the strength and concentration of Brønsted acid sites (BAS) of aluminosilicates. Adsorption of $\mathrm{CO}$ at $77 \mathrm{~K}$ is accompanied by a shift of a.b. $\mathrm{OH}$-groups to the low-frequency region $\left(\Delta \nu \mathrm{OH}^{\mathrm{OH}} \ldots \mathrm{CO}\right)$ caused by the perturbation of valence vibrations of $\mathrm{OH}$

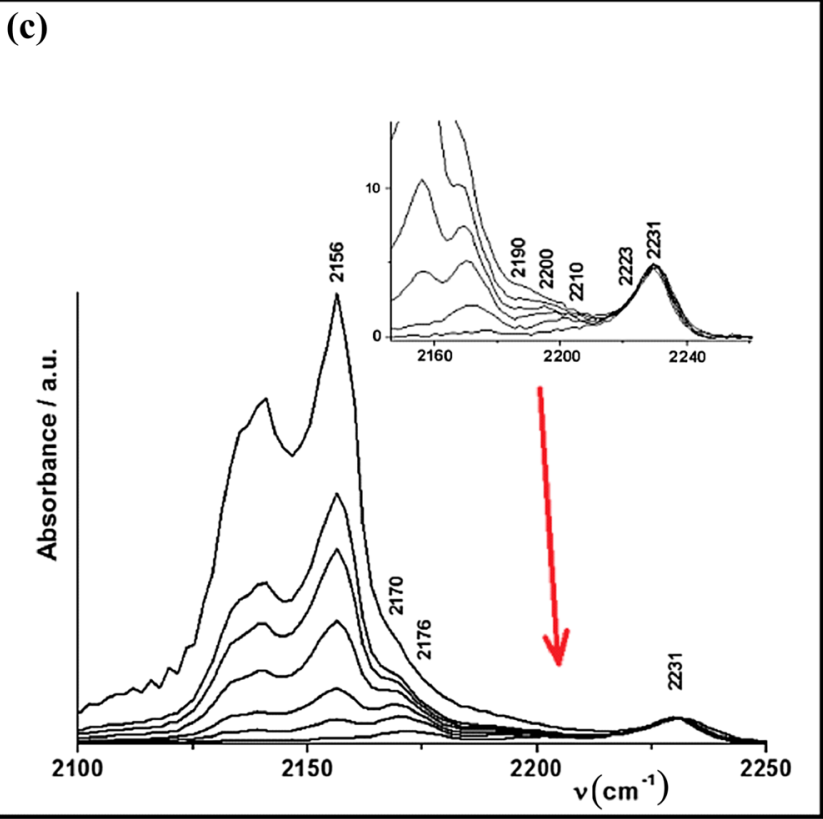

tra carbonyl regions between the initial aluminosilicate ASM-80 and those with increased dosage of adsorbed CO from 0.1 (bottom curve) to 4 mbar (top curve) at liquid nitrogen temperature

groups due to the formation of a hydrogen bond with $\mathrm{CO}$. At that, the larger the magnitude of the shift, the stronger the center is shifts of a.b. OH groups in the formation of the hydrogen bond and the corresponding a.b. adsorbed $\mathrm{CO}$ for samples of aluminosilicates are presented in Table 3.

The BAS concentration is detailed in Table 3. As expected, the ASM-40 sample exhibits the highest BAS concentration. as the $\mathrm{Si} / \mathrm{Al}$ ratio increases, BAS concentrations decrease.

According to $\mathrm{CO}$ adsorption data (Fig. 5c), 5 types of Lewis acid sites are observed on the surface of all samples. In the spectrum of the samples, there are a.b. at 2223 and $2231 \mathrm{~cm}^{-1}$, characteristic of $\mathrm{CO}$ complexes with $\mathrm{Al}^{3+}$ ions in pentahedron environment being specific structure defects of aluminosilicates and zeolites; a.b. at $2210-2212 \mathrm{~cm}^{-1}$, 


\section{(a)}<smiles>CCCO[CH+]C(=O)[CH+]Nc1cncc(C)c1</smiles>

(b)<smiles>CCCCO[CH+]CC(=O)[CH+]N</smiles>

Scheme 1 The reaction of propanol (a) and butanol (b) with formaldehyde and ammonia

a.b. at 2202-2200 and $2190 \mathrm{~cm}^{-1}$, which are characteristic of $\mathrm{CO}$ complex with $\mathrm{Al}^{3+}$ ions, apparently, clusters of aluminum oxide.

The types and concentration of LAS are presented in Table 3. In fact, with increasing Si/Al ratio, the concentration of LAS decreases, as the aluminum content in the material is reduced.

\section{Catalytic properties of mesoporous aluminosilicates in the synthesis of 3,5-dialkylpyridines}

The reaction of alcohols (propanol, butanol) with formaldehyde and ammonia in the presence of mesoporous aluminosilicates proceeds to form predominantly 3,5-dialkylpyridine (Scheme 1): 3,5-lutidine (using $n$-propanol) and 3,5-diethylpyridine (using $n$-butanol).

In addition to these major compounds, imines and alkylamines (propylamine, butylamine) were detected in the reaction products as well, designated as "light". In the reaction with propanol, along with 3,5-lutidine, 3,4-lutidine and the mixture trialkylamines with dominating 2-ethyl-3,5-dimethylpyridine were formed.

As shown in Table 4, the ASM-40 mesoporous aluminosilicate sample exhibited high selectivity in the synthesis of 3,5 - dialkylamine: selectivity for 3,5-lutidine at $300{ }^{\circ} \mathrm{C}$ is $94 \%$, and $86 \%$ for 3,5-diethylpyridine. The conversion of the alcohol is $25 \%$ for propanol and $22 \%$ for butanol. With increasing temperature up to $400{ }^{\circ} \mathrm{C}$, conversion of the alcohol increased (70 and 62\%, respectively), and the number of such byproducts as light and various alkylpyridine increased in the reaction mass, resulting in the decreased selectivity of the dialkylpyridine formation ( $74 \%$ and $63 \%$ ).

The effect of the space velocity (WHSV) on alcohol conversion and on the composition of the products is shown on the example of the reaction of propanol with formaldehyde and ammonia in the presence of the ASM-40 sample (Table 5).

With the increase in WHSV from 2 to $14 \mathrm{~h}^{-1}$, the contact time between active sites of the catalyst and the
Table 4 Interaction of $\mathrm{C}_{3}-\mathrm{C}_{4}$ alcohols with formaldehyde and ammonia in the presence of mesoporous aluminosilicates (reaction conditions: catalyst ASM-40, alcohol: formaldehyde: ammonia $=1.0: 0.8: 3.0($ molar ratio $)$, WHSV $\left.=7 \mathrm{~h}^{-1}\right)$

\begin{tabular}{|c|c|c|c|c|c|}
\hline \multirow[t]{2}{*}{ Alcohol } & \multirow[t]{2}{*}{$T\left({ }^{\circ} \mathrm{C}\right)$} & \multirow{2}{*}{$\begin{array}{l}X \text { (alco- } \\
\text { hol) (\%) }\end{array}$} & \multicolumn{3}{|c|}{ Selectivity (\%) } \\
\hline & & & "Light" & $\begin{array}{l}\text { 3,5-Dialkyl- } \\
\text { pyridine }\end{array}$ & $\begin{array}{l}\text { Other } \\
\text { alkyl-pyri- } \\
\text { dines }\end{array}$ \\
\hline Propanol & 300 & 25 & 3 & 97 & 0 \\
\hline Propanol & 350 & 45 & 5 & 84 & 11 \\
\hline Propanol & 400 & 70 & 6 & 79 & 15 \\
\hline Butanol & 300 & 22 & 3 & 86 & 11 \\
\hline Butanol & 400 & 62 & 11 & 63 & 26 \\
\hline
\end{tabular}

Table 5 The effect of WHSV on the conversion of propanol and on the selectivity of the product formation in the presence of ASM-40 aluminosilicate (reaction conditions: $T=300{ }^{\circ} \mathrm{C}$, $\mathrm{C}_{3} \mathrm{H}_{7} \mathrm{OH}: \mathrm{CH}_{2} \mathrm{O}: \mathrm{NH}_{3}=1.0: 0.8: 3.0$ (molar ratio)

\begin{tabular}{|c|c|c|c|c|}
\hline \multirow[t]{2}{*}{$\overline{\text { WHSV }\left(\mathrm{h}^{-1}\right)}$} & \multirow{2}{*}{$\begin{array}{l}X \text { (pro- } \\
\text { panol) } \\
(\%)\end{array}$} & \multicolumn{3}{|c|}{ Selectivity (\%) } \\
\hline & & $\begin{array}{l}\text { "Light" } \\
\text { products }\end{array}$ & 3,5-Lutidine & $\begin{array}{l}\text { Other } \\
\text { alkyl-pyri- } \\
\text { dines }\end{array}$ \\
\hline 2 & 36 & 18 & 72 & 10 \\
\hline 4 & 30 & 10 & 85 & 5 \\
\hline 7 & 25 & 3 & 97 & 0 \\
\hline 14 & 5 & 6 & 94 & 0 \\
\hline
\end{tabular}

reacting molecules is reduced, and the conversion of propanol decreased from 36 to $5 \%$. The reaction proceeds most selectively with moderate conversion of the alcohol, if the WHSV value is $7 \mathrm{~h}^{-1}$.

A decrease of WHSV up to $2-4 \mathrm{~h}^{-1}$ led to a decrease of the selectivity for 3,5-lutidine, as the content of "light" compounds and alkylpyridines increased in the reaction mass.

The most selectively 3,5-dimethylpyridine (97\%) is formed at $300{ }^{\circ} \mathrm{C}, 7 \mathrm{~h}^{-1}$ (Table 5). In contrast with the well-known method [38] for the preparation of 
Table 6 The effect of the ratio of $\mathrm{Si} / \mathrm{Al}$ in a mesoporous aluminosilicate on its catalytic properties in the synthesis of 3,5-dimethylpyridine (reaction conditions: $400{ }^{\circ} \mathrm{C}$, WHSV $=7 \mathrm{~h}^{-1}$, propanol: formaldehyde: ammonia $=1.0: 0.8: 3.0($ molar ratio $))$

\begin{tabular}{|c|c|c|c|c|c|}
\hline \multirow[t]{2}{*}{$\mathrm{Si} / \mathrm{Al}$} & \multirow{2}{*}{$\begin{array}{l}\text { Concentra- } \\
\text { tion BAS } \\
(\mu \mathrm{mol} / \mathrm{g})\end{array}$} & \multirow{2}{*}{$\begin{array}{l}X(\text { propanol }) \\
(\%)\end{array}$} & \multicolumn{3}{|c|}{ Selectivity (\%) } \\
\hline & & & "Light" & $\begin{array}{l}\text { 3,5- Luti- } \\
\text { dine }\end{array}$ & $\begin{array}{l}\text { Other } \\
\text { alkyl- } \\
\text { pyridines }\end{array}$ \\
\hline 40 & 40 & 70 & 6 & 79 & 15 \\
\hline 80 & 28 & 45 & 21 & 59 & 20 \\
\hline 120 & 22 & 30 & 32 & 44 & 24 \\
\hline
\end{tabular}

3,5-dimethylpyridine over zeolite La-ZSM-5 ( $\mathrm{Si} / \mathrm{Al}=15)$, the usage of mesoporous aluminosilicates makes it possible to conduct the reaction at a higher WHSV, with smaller amounts of catalyst and without solvent.

In this context it should be noted that synthesis of ZSM-5 pentasil is quite a complex process, requiring the use of expensive templates. Furthermore, methanol is used as a solvent in the method [38], which is known to be strong nerve and vascular poison with a pronounced cumulative effect.

It was noted in the article [51] that the acidity of the catalyst is important for carrying out the reaction of cyclocondensation with the formation of alkylpyridine.

To determine the influence of acidity of mesoporous materials on their catalytic properties in the reaction of propanol with formaldehyde and ammonia, the activity and selectivity of the three samples of ASM aluminosilicate, with various molar ratio $\mathrm{Si} / \mathrm{Al}(\mathrm{Si} / \mathrm{Al}=40,80,120)$ (Table 6) have been studied.

The sample with molar ratio $\mathrm{Si} / \mathrm{Al}=40$ containing the largest number of acid sites has proved to exhibit the maximum activity in the reaction.

The sample with molar ratio $\mathrm{Si} / \mathrm{Al}=40$ containing the largest number of acid sites has proved to exhibit the maximum activity in the reaction. With an increase of the molar ratio of $\mathrm{Si} / \mathrm{Al}$ to 120 , the conversion of propanol decreases more than two times, which is associated with a decrease of the concentration of acid sites by decreasing the concentration of $\mathrm{Al}$ atoms in the aluminosilicate framework. This also reduced the selectivity of the formation of 3,5-dimethylpyridine and increased the number of products of linear condensation (alkylamines, imines) and isomeric alkylpyridines.

\section{Conclusions}

1. The detailed investigation of the two-step sol-gel synthesis of aluminosilicates with the $\mathrm{Si} / \mathrm{Al}$ ratio of 40,80 , and 120 , revealed that in the first step, due to a close $\mathrm{pH}$ value of $\sim 3$, there are no large differences in supersaturation in the embryos. Thus, primary particles of sol are formed, close in size in the range of 3-5 $\mathrm{nm}$. Upon transition to an alkaline medium, the primary particles of the sol combine to form secondary homogeneous agglomerates of $10-15 \mathrm{~nm}$ in size with loose packing. Therefore, mesopores with a narrow size distribution emerge in the formed aluminosilicates. An increase in the $\mathrm{Si} / \mathrm{Al}$ ratio from 40 to 120 results in a slight decrease in the specific surface area from 670 to $520 \mathrm{~m}^{2} / \mathrm{g}$ and an increase in the mesopore volume from 0.50 to $0.80 \mathrm{~cm}^{3} / \mathrm{g}$.

2. The presented research indicates that, due to the limited possibility of introducing aluminum atoms into the silicate framework, the number of the latter in the ASM-40 and ASM-80 samples is relatively equal. The remaining aluminum atoms in the ASM-40 sample are present, presumably in the form of metal oxide clusters, that is why the total acidity values for the ASM-40 and ASM80 samples are relatively equal. An increase in the $\mathrm{Si} /$ $\mathrm{Al}$ ratio from 40 to 120 leads to a decrease in the total acidity in ammonia from 554 to $324 \mu \mathrm{mol} / \mathrm{g}$.

3. The results of the investigation of catalytic properties of ASM mesoporous aluminosilicates in the reaction of propanol and butanol with formaldehyde and ammonia reveal that synthesis of dialkylpyridines was conducted most selectively on the ASM-40 sample. The selectivity of the formation of 3,5-dimethylpyridine (in the reaction with propanol) is $97 \%$ at conversion of the alcohol $25 \%$, and the selectivity for 3,5-diethylpyridine (in the reaction with butanol) makes $86 \%$ at conversion of ethanol $22 \%$.

The interrelation of activity and selectivity of mesoporous aluminosilicates with their acidity has been shown. On the example of samples of mesoporous aluminosilicate ASM with different $\mathrm{Si} / \mathrm{Al}$ molar ratio $(\mathrm{Si} /$ $\mathrm{Al}=40,80,120$ ), it was established that the maximum activity in the reaction is exhibited by the sample with a molar ratio $\mathrm{Si} / \mathrm{Al}=40$, which contains the largest number of acid sites. With an increase in the molar ratio of $\mathrm{Si} / \mathrm{Al}$ to 120 , the alcohol conversion decreases, which is due to a decrease in the concentration of acid sites due to the concentration reduction of $\mathrm{Al}$ atoms in the aluminosilicate framework. Moreover, the selectivity of the formation of 3,5-dimethylpyridine is also reduced.

Conditions for the preparation of 3,5-dialkylpyridines with a maximum selectivity were determined: $300{ }^{\circ} \mathrm{C}$, $\mathrm{WHSV}=7 \mathrm{~h}^{-1}$, molar ratio of alcohol: formaldehyde: ammonia $=1.0: 0.8: 3.0$.

Acknowledgements This work was supported by the Russian Science Foundation under grant RSF-DST No. 16-43-02010. The analysis of the obtained compounds was performed with the use of Collective Usage Centre "Agidel" at Institute of Petrochemistry and Catalysis of the Russian Academy of Sciences. Electron microscopy characterization was 
performed in the Department of Structural Studies of Zelinsky Institute of Organic Chemistry, Moscow.

Open Access This article is distributed under the terms of the Creative Commons Attribution 4.0 International License (http://creativeco mmons.org/licenses/by/4.0/), which permits unrestricted use, distribution, and reproduction in any medium, provided you give appropriate credit to the original author(s) and the source, provide a link to the Creative Commons license, and indicate if changes were made.

\section{References}

1. Kumar A, Yadav N, Bhatt M, Mishra NK, Chaudhary P, Singh R (2015) Sol-gel derived nanomaterials and it's applications: a review. Res J Chem Sci 5:98-105 http://www.isca.in/rjcs/Archi ves/v5/i12/10.ISCA-RJCS-2015-152.pdf

2. Norfazilah W, Ismail W (2016) Sol-gel technology for innovative fabric finishing. J Sol Gel Sci Technol 78:698-707

3. Kakihana M (1996) "Sol-gel" preparation of high temperature superconducting oxides. J Sol Gel Sci Technol 6:7-55

4. Barbé CJ, Cassidy DJ, Triani G, Latella BA, Mitchell DRG, Bartlett JR (2003) Low temperature bonding of ceramics by sol-gel processing. J Sol Gel Sci Technol 26:1145-1150

5. Reisfeld R, Saraidarov T (2006) Innovative materials based on sol-gel technology Optic Mater 28:64-70

6. Wang D, Bierwagen GP (2009) Sol-gel coatings on metals for corrosion protection. Prog Org Coat 64:327-338

7. Owens GJ, Singh RK, Foroutan F, Alqaysi M, Han C-M, Mahapatra C, Kim H-W, Knowles JC (2016) Sol-gel based materials for biomedical applications. Prog Mater Sci 77:1-79

8. Beltra'n-Osuna AA, Perilla JE (2016) Colloidal and spherical mesoporous silica particles: synthesis and new technologies for delivery applications. J Sol Gel Sci Technol 77:480-496

9. Guo X, Zhang Q, Ding X, Shen Q, Wu C, Zhang L, Yang H (2016) Synthesis and application of several sol-gel-derived materials via sol-gel process combining with other technologies. J Sol Gel Sci Technol 79:328-358

10. Miller JB, Ko EI (1997) Control of mixed oxide textural and acidic properties by the sol-gel method. Catal Today 35:269-292

11. Brinker CJ, Scherer GW (1990) Sol-Gel Science, the physics and chemistry of sol-gel processing. Academic press, Boston

12. Chuang KC, Young GW, Benslay RM (1992) Advanced fluid catalytic cracking technology. In: AlChE symposium series, vol 291. American Institute of Chemical Engineers, New York, p 30

13. Ward JW (1983) Design and preparation of hydrocracking catalysts. Stud Surf Sci Catal 16:587-618

14. Deldari H (2005) Suitable catalysts for hydroisomerization of long-chain normal paraffins. Appl Catal A 293:1-10

15. Twaiq FA, Mohamed AR, Bhatia S (2003) Liquid hydrocarbon fuels from palm oil by catalytic cracking over aluminosilicate mesoporous catalysts with various $\mathrm{Si} / \mathrm{Al}$ ratios. Microporous Mesoporous Mater 64:95-107

16. Grigor'eva NG, Filippova NA, Agliullin MR, Kutepov BI, Narender N (2017) Crystalline and amorphous aluminosilicates with different pore structures for the synthesis of pyridines. J Chem Res 41:253-261

17. Wan Y, Zhao D (2007) On the controllable soft-templating approach to mesoporous silicates. Chem Rev 107:2821-2860

18. Tueysuez H, Schueth F (2012) Ordered mesoporous materials as catalysts. Adv Catal 55:127-239

19. Soler-Illia GJ de AA, Sanchez C, Lebeau B, Patarin (2002) Chemical strategies to design textured materials: from microporous and mesoporous oxides to nanonetworks and hierarchical structures. J Chem Rev 102:4093-4138

20. Bonifacio LD, Lotsch BV, Ozin GA (2010) Periodic mesoporous materials: holes filled with opportunities. In: Andrews D, Scholes G, Wiederrecht G (eds) comprehensive nanoscience and technology, 1st edn. Academic Press 5:69-125 https://www. elsevier.com/books/comprehensive-nanoscience-and-techn ology/andrews/978-0-12-374390-9

21. Pouxviel JC, Boilot JP, Mackenzie JD, Ulrich DR (1988) Ultrastructure processing of advanced ceramics. Wiley, New York

22. Yoldas BE, Partlow DP (1988) Formation of mullite and other alumina-based ceramics via hydrolytic polycondensation of alkoxides and resultant ultra- and microstructural effects. J Mater Sci 23:1895-1900

23. Pierre AC (1997) Porous sol-gel ceramics. Ceram Int 23:229-238

24. de Witte BM, Uytterhoeven JB (1996) Acid and alkaline sol-gel synthesis of amorphous aluminosilicates, dry gel properties, and their use in probing sol phase reactions. J Colloid Interface Sci 181:200-207

25. Okada K, Tomita T, Kameshima Y, Yasumori A, Yano T, Mackenzie JD (2000) Effect of preparation conditions on the porous properties of coprecipitated $\mathrm{Al}_{2} \mathrm{O}_{3}-\mathrm{SiO}_{2}$ xerogels synthesized from aluminium nitrate nonahydrate and tetraethylorthosilicate. Microporous Mesoporous Mater 37:355-364

26. Hernandez C, Pierre AC (2001) Evolution of the texture and structure of $\mathrm{SiO}_{2}-\mathrm{Al}_{2} \mathrm{O}_{3}$ xerogels and aerogels as a function of the $\mathrm{Si}$ to Al molar ratio. J Sol Gel Sci Technol 20:227-243

27. Jones SD, Pritchard TN, Lander DF (1995) Physical properties of sol-gel aluminosilicates. Microporous Mater 3:419-431

28. Okada K, Tomita T, Kameshima Y, Yasumori A, Mackenzie JD (1999) Porous properties of coprecipitated $\mathrm{Al}_{2} \mathrm{O}_{3}-\mathrm{SiO}_{2}$ xerogels prepared from aluminium nitrate nonahydrate and tetraethylorthosilicate. J Mater Chem 9:1307-1312

29. Vit Z, Šolcová O (2006) Synthesis and properties of mesoporous silica-alumina with narrow pore size distribution obtained without use of pore-regulating agents. Microporous Mesoporous Mater 96:197-204

30. Agliullin MR, Danilova IG, Faizullin AV, Amarantov SV, Bubennov SV, Prosochkina TR, Grigor'eva NG, Paukshtis EA, Kutepov BI (2016) Sol-gel synthesis of mesoporous aluminosilicates with a narrow pore size distribution and catalytic activity thereof in the oligomerization of dec-1-ene. Microporous Mesoporous Mater 230:118-127

31. Henry GD (2004) De novo synthesis of substituted pyridines. Tetrahedron 60:6043-6061

32. Krishna VV, Mohan Kandepi, Nama Narender (2012) Synthesis of $N$-heterocyclic compounds over zeolite molecular sieve catalysts: an approach towards green chemistry. Catal Sci Technol 2:471-487

33. Shimizu S, Watanabe N, Kataoka T, Shoji T, Abe N, Morishita S, Ichimura $H$ (2012) Pyridine and pyridine derivatives. Encycloped Ind Chem 30:558-589

34. Ronald Lee Amey (1999) Preparation of 3,5-lutidine. EP 0929523 A1

35. Chandrakala M, Ramachandra Rao R, Kulkarni SJ, Subrahmanyam M, Raghavan KV (1998) Selective preparation of 3,5-diethylpyridine from $n$-butanol, formaldehyde and ammonia over modified ZSM-5 catalysts. Indian J Chem NISCAIRCSIR 37A(4):323-327. http://nopr.niscair.res.in/handle/12345 $6789 / 39996$

36. van der Gaag F J, Louter F, Oudejans JC, van Bekkum H (1986) Reaction of ethanol and ammonia to pyridines over zeolite ZSM5. Appl Catal 26:191-201

37. Kulkarni SJ, Ramachandra Rao R, Subba Rao YV, Subrahmanyam M, Rama Rao AV (1996) Synthesis of 3,5-lutidine from propionaldehyde over modified ZSM-5 catalysts. Appl Catal A 136:11-16 
38. Ramachandra Rao R, Srinivas N, Kulkarni SJ, Subrahmanyam M, Raghavan KV (1997) A new route for the synthesis of 3,5-lutidine over modified ZSM-5 catalysts. Appl Catal A 161:137-142

39. Dieterich D, Braden R (1972) Method for the preparation of 3,5-dialkylpyridines USSR Patent 363247

40. Grayson JI, Dinkel R (1984) An improved liquid-phase synthesis of simple alkylpyridines. Helv Chim Acta 67(8):2100-2110

41. Zellner RJ (1958) Production of heterocyclic nitrogen compounds US Patent 2851461

42. Antonova VV, Titova NA, Promonenkov VK, Ustaqushikov BF (1979) Method or the preparation of 3,5-dialkylpyridine. USSR Certificate of authorship 652176

43. Grigor'eva NG, Filippova NA, Agliullin MR, Kutepov BI, Narender N, (2017) J Chem Res 41:253-261

44. Svergun DI, Konarev PV, Volkov VV (2000) A small angle $\mathrm{X}$-ray scattering study of the droplet-cylinder transition in oilrich sodium bis(2-ethylhexyl) sulfosuccinate microemulsions. J Chem Phys 113:1651-1665

45. Kachala VV, Khemchyan LL, Kashin AS, Orlov NV, Grachev AA, Zalesskiy SS, Ananikov VP (2013) Target-oriented analysis of gaseous, liquid and solid chemical systems by mass spectrometry, nuclear magnetic resonance spectroscopy and electron microscopy. Russ Chem Rev 82:648-685

46. Niwa M, Katada N, Okumura K (2010) Characterization and design of zeolite catalysts solid acidity, shape selectivity and loading properties. Springer, Amsterdam
47. Travkina OS, Agliullin MR, Filippova NA, Khazipova AN, Danilova IG, Grigor'eva NG, Narender N, Pavlov MI, Kutepov BI (2017) Template-free synthesis of high degree crystallinity zeolite Y with micro-meso-macroporous structure. RSC Adv 7:32581-32590

48. Bordiga S, Ugliendo P, Damin A, Lamberti C (2001) Hydroxyls nests in defective silicalites and strained structures derived upon dehydroxylation: vibrational properties and theoretical modeling. Top Catal 15:43-52

49. Trombetta M, Busca G, Rossini S, Piccoli V (1998) FTIR studies on light olefin skeletal isomerization catalysis: III. Surface acidity and activity of amorphous and crystalline catalysts belonging to the $\mathrm{SiO}_{2}-\mathrm{Al}_{2} \mathrm{O}_{3}$ system. J Catal 179:581-596

50. Paukshtis EA, Yurchenko EN (1983) Study of the acid-base properties of heterogeneous catalysts by infrared spectroscopy. Russ Chem Rev 52:242-258

51. Suresh K, Reddy K, Srinivasakannan C, Raghavan KV (2012) Catalytic vapor phase pyridine synthesis: a process review. Catal Surv Asia 16(1):28-35

Publisher's Note Springer Nature remains neutral with regard tojurisdictional claims in published maps and institutional affiliations. 